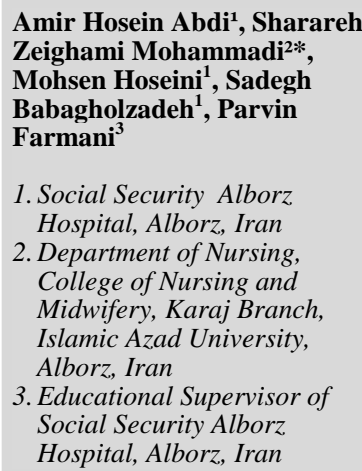

Alborz Univ Med J (AUMJ) 2018 February; 7(1):15-23

http://aums.abzums.ac.ir $(p=0.010)$

\section{Mortality and Length of Hospital Stay in Elderly with Hospital -Acquired Pressure Ulcer in Alborz Hospital of Karaj (2012)}

Received: 15 Jul. 2017 ; Accepted: 4 Jan. 2018

Introduction: Pressure ulcers are serious health problems, common but preventable and defined as care quality indicator for health care provider services. Pressure ulcers had negative consequences for patients and healthcare systems. The aim of this study was to determine mortality and length of hospital stay in elderly people with hospital acquired pressure ulcers in Alborz Hospital of Karaj 2012.

Method: 132 records belong to elderly people with hospital acquired pressure ulcers of Alborz Hospital in Karaj 1391, through convenience sampling were studied retrospectively. Include criteria was age $>65$ years, minimum 2-day stay in hospital and hospital acquired pressure ulcers. Data were analysis by descriptive statistics, t-test, ANOVA and chi-square tests.

Results: The findings indicated that $15.2 \%$ of elderly patients with hospital acquired pressure ulcers was died. Mortality significantly was associated with hospitalized in intensive wards $(p<0.001)$ grade of pressure ulcers $(p<0.001)$ and neurological problems $(p=0.045)$. Mean length of hospital stay was $6.8 \pm 7$ days with a range from 2 to 60 days. Mean length of hospital stay significantly was higher in elder people hospitalized in intensive wards $(p<0.001)$, patients who died $(p<0.001)$ and pressure ulcer grade III

Discussion: Focus on strategies for the prevention of ulcers, particularly in older adults hospitalized in intensive wards, neurological problems and prevent progression of ulcers can help to reduce length of hospital stay and mortality in these patients.

Keywords: Elderly, Pressure ulcers, Mortality, Length of hospital stay 


\section{ميزان مركى و مير و طول مدت بسترى سالمندان مبتلا به زخهم فشارى كسبشده

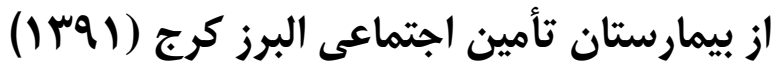

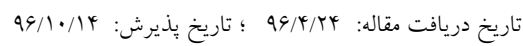

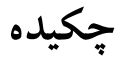

زمينه و هدف: زخم فشارى از مشكلات جدى، شايع اما قابل ييشخيرى بهداشتى و يك شاخص تعريفشده كيفيت مراقبت براى سازمانهاى ارائهدهنده خدمات بهداشتى است. زخم فشارى تبعات منفى را متوجـه بيمـاران و سيسـتمهـاى درمـانى مى كند. مطالعه حاضر با هدف تعيين ميزان مركىومير و طول مدت بسترى سالمندان مبتلا به زخــم فشـارى كسـبشــده از

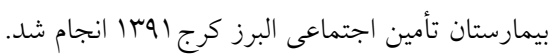
مواد و روش ها: برا برونده متعلق به سالمندان داراى زخم فشارى كسبشده از بيمارستان تخصصى البـرز كـرج در سـال اوها طى يكى مطالعه توصيفى كذشتهنخر به روش نمونه گيرى آسان موردبررسى قرار كرفت. شرط ورود به مطالعسه سـن بالاى هو سال، حداقل دو روز اقامت در بيمارستان و زخم فشارى اكتسابى از بيمارستان بود. اطلاعات با اسـفاده از آمـار توصيفى، تى تست، آناليز واريانس يكىطرفه و كاى دو تحليل گرديد.

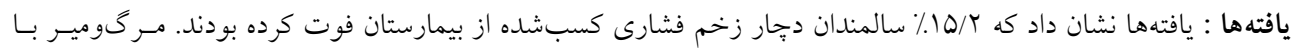

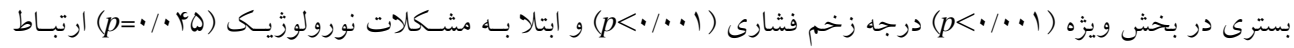

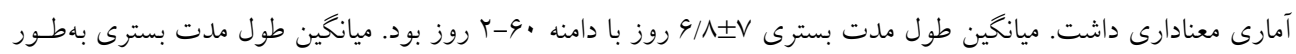

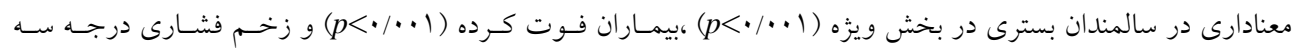
بيشتر بود. $(p=\cdot / \cdot)$ نتيجه گيرى: تمركز بر استراتزىهاى بيشخيرى از ايجاد زخم در سالمندان بسـترى در بخـشهـاى ويـزّه، داراى مشـكلات نورولوزيك و ممانعت از ييشرفت زخم مىتواند به كاهش طول اقامت و مرگومير اين بيماران كمك نمايد. كلمات كليدى: سالمندى، زخم فشارى، مرگومير، طول مدت بسترى

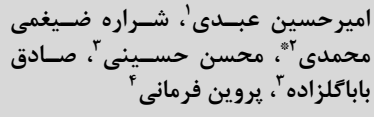

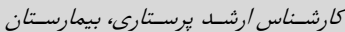

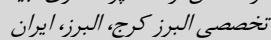

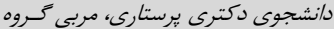

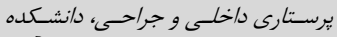

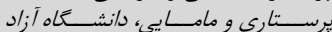

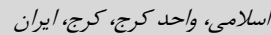

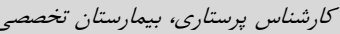

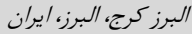

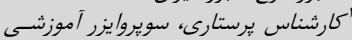

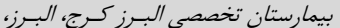
ايران

\footnotetext{
政
}$$
\text { (1) }
$$ 
ساكروم، ناحيه اسكايولا، باسن، ايسكيوم، باشنه پِا و انخشت شسـت

كمتر كسى به مراقبت از بيمـاران يرداختهـ و بـا زخـــم فشـارى

سن، جنس مذكر، بى تحركى، بيماران تحت بيمارىهاى داخلى،

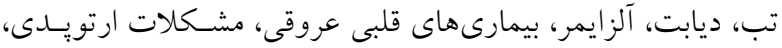
فشارخون، فلج، بيمارىهاى تنفسى، ابتلا به عفونت، انواع تـودههـا،

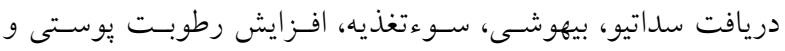

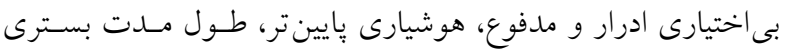

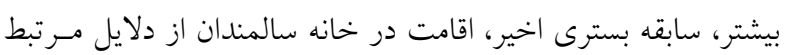

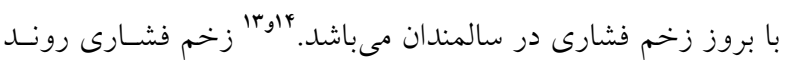
التيـامى آهسـتهاى دارد و در صـورت عـدم درمـان سـبب ايجــاد

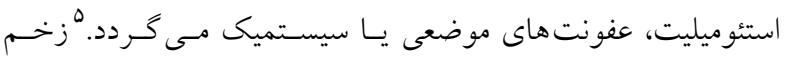
فشارى در سالمندان سبب كاهش كيفيت زندگى، درد، طولانى شدن

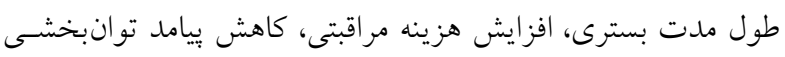
و بروز مشكلات بالقوه بيتجيده مى شود. 10

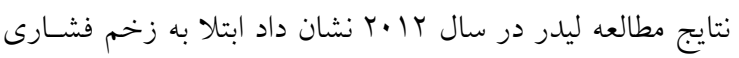

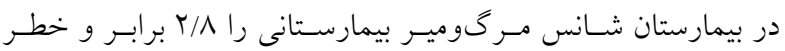

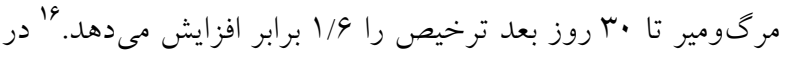
مطالعـه السدردن و همكــاران سا درصـد سـالمندان" و در مطالعسه. كوكس در سال || +r حدود · ا درصد سالمندان دجار زخم فشارى فوت كرده بودند. نتايج برخى مطالعات داخـل و خـارج از كشـور نشـان داد كـهـ ميانخين طول مدت بسترى بيماران در صورت ابتلا به زخم فشـارى

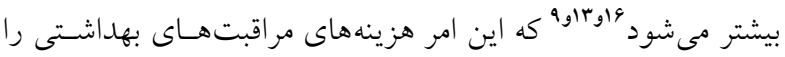
افزايش مىدهد. مطالعه ديلسى در سـال r Y ب نشـان داد كـه هزينـه

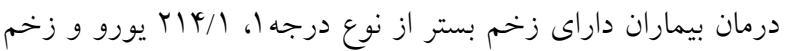

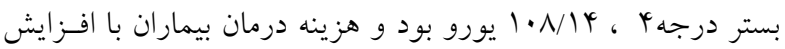

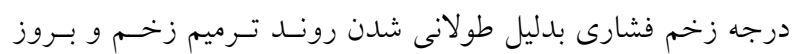
عوارض بيشتر مىشود.

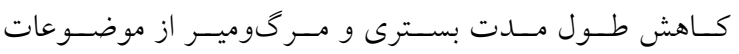
جالشبرانگيز در بيماران دجار زخم فشارى است، شناخت و كنتـرل ريسك فاكتورهاى مرتبط با مرگومير و طول مدت بسترى در بهبود

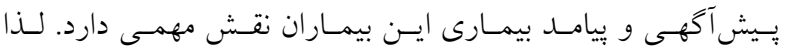

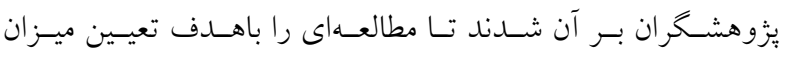

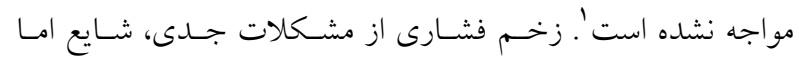
قابل بيشخيرى بهاداشتى، "r، همجنين يك شاخص تعريف شده كيفيت

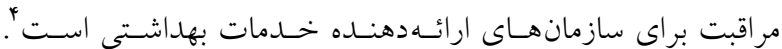
درزمينه اتيولوزى زخم فشارى دو تئورى بيانشده است. در تئسورى اول زخم فشارى براثر فشار مستمر بر بافتهاى نرم ميان برجستخى استخوان و سطوح خارجى ايجاد مى شود. ايسكمى ناشى از انســاد

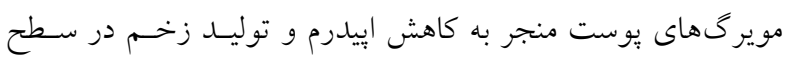

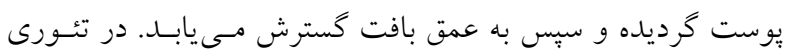

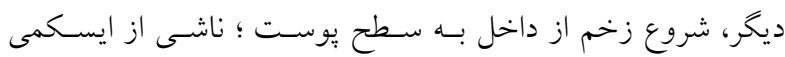
موير گهاى ناحيه اتصال استخوان و بافت نرم مىباشد كه ابتدا مرى در بافتههاى نرم و سيس در استخوان اتفاق مىافتد. در لمس موضع

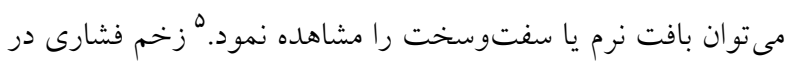
بيمارانى كه به مدت طولانى در بيمارستان يا منزل بسترى مىشـوند

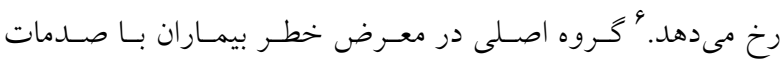

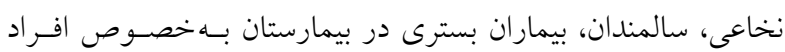

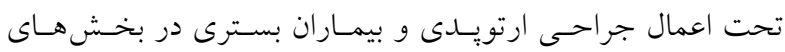
مراقبتهاى ويزه هستند. v سالمندى ريسك فاكتورى مهم در ايجاد زخم فشارى محسـوب

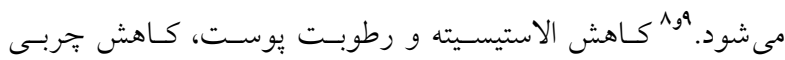
زيريوست، آتروفى غدد آيوكرين وسباسه، خشكى يوست و كـاهش

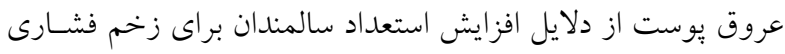

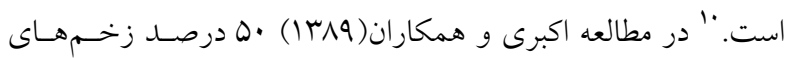
فشارى در سنين بالاى •4 سال ايجادشده بود.' علىرغم افزايش آكاهى از تبعات بالينى و بـار اقتصـادى زخــم

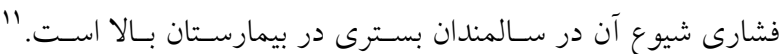

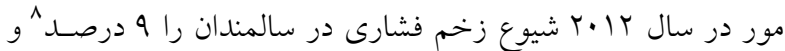

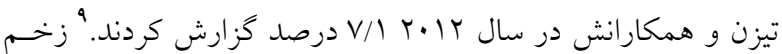
فشارى از درجهيك تا جهاردر سالمندان مشاهده مىشود. در مطالعه

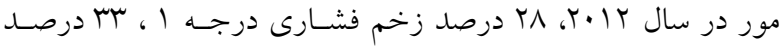

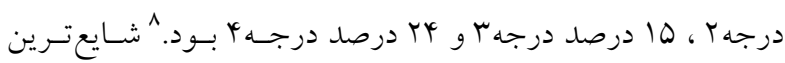
محل هاى وقـوع زخــم فشـارى در بــدن ناحيـه يشـت سـر، ناحيـه 
هم:جنين به مسئولين بيمارسـتان اطمينـان داده شـــ كـه در صـورت

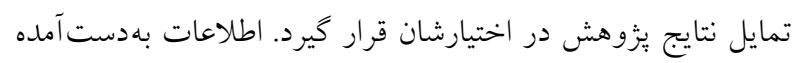

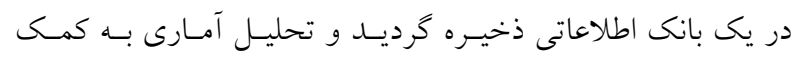

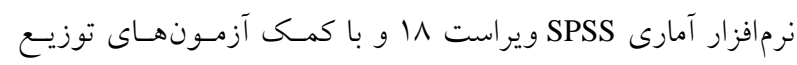

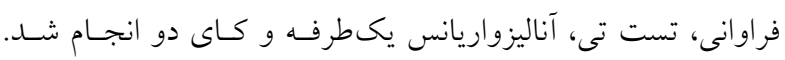

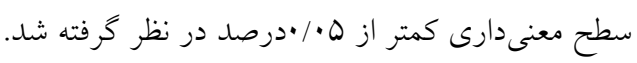

\section{يافته ها}

همان كونه كه جدول شماره ا نشـان داد Q ه درصــ بيمـاران

داراى زخم فشارى، مرد بودند. ميانخين و انحراف معيار سن بيماران

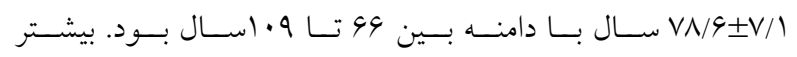

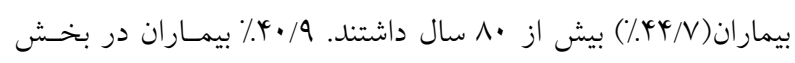

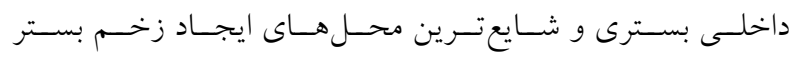

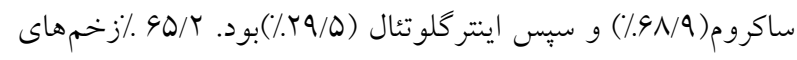

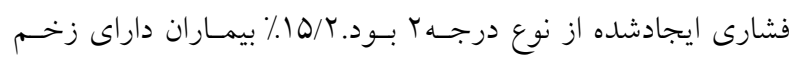

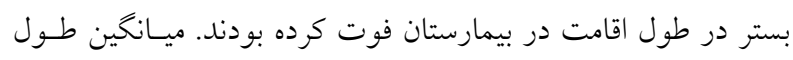

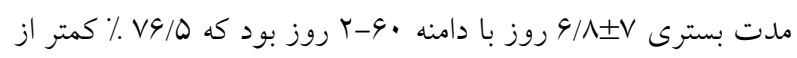

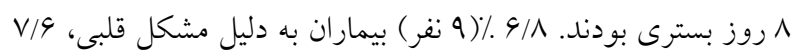

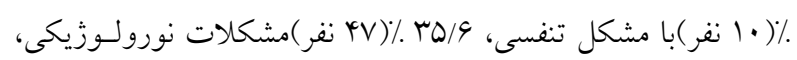

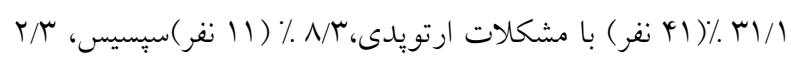

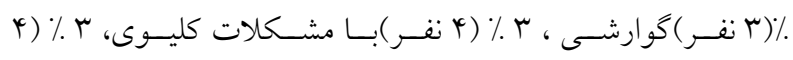

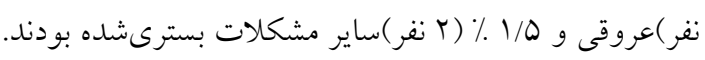

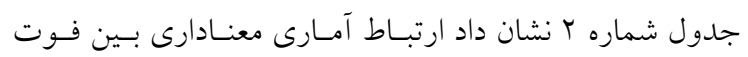
بيماران و بخش محل بسترى مشاهده شد، بطورى كه بيشتر بيمـاران

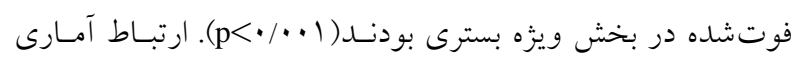

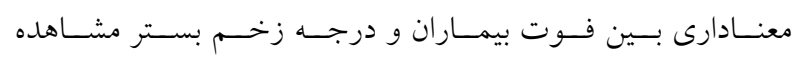

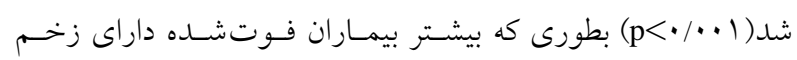

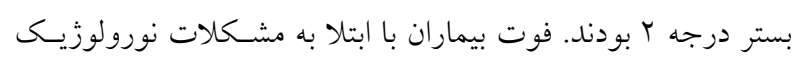

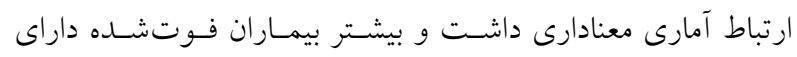

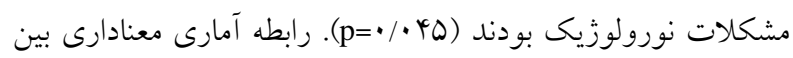

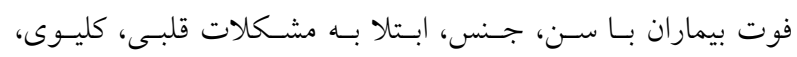

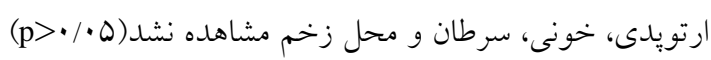

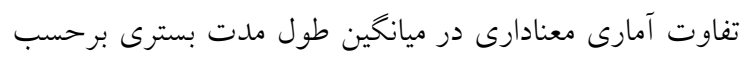

مركَومير بيمارستانى و طول مدت بسترى سـالمندان مبتلابـهـ زخــم

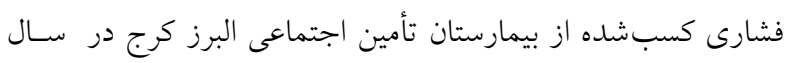

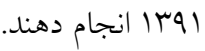

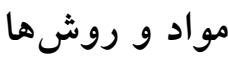

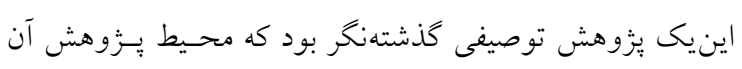

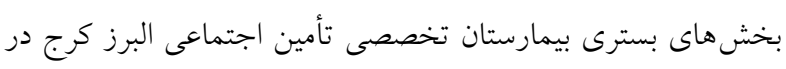

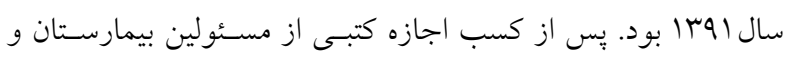

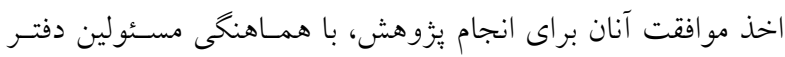

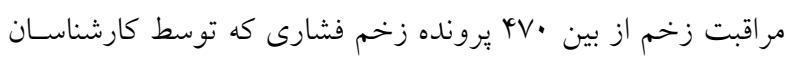

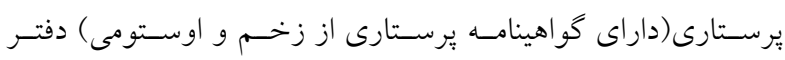

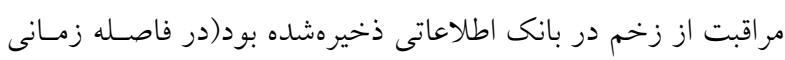

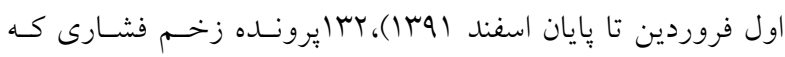

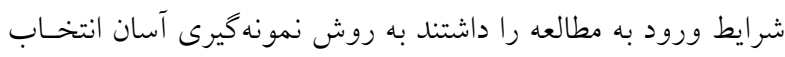

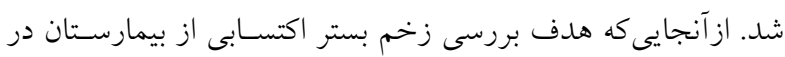

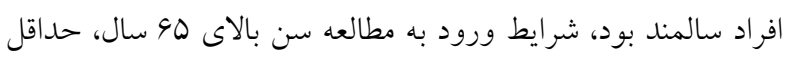

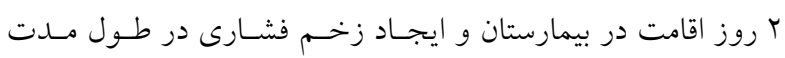

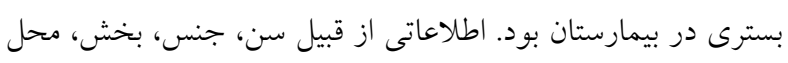

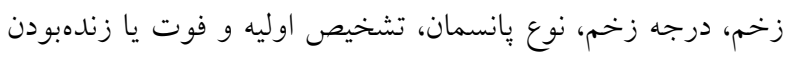

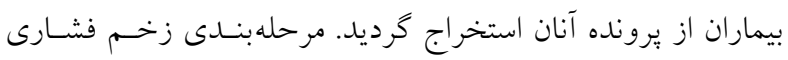

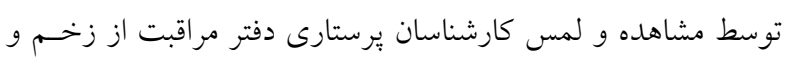

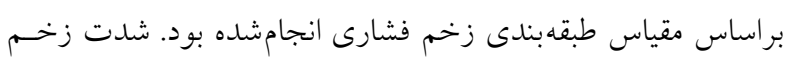

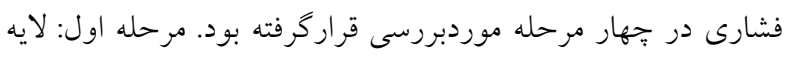

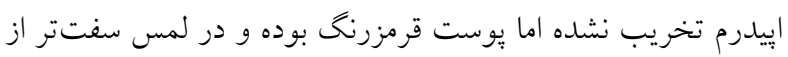

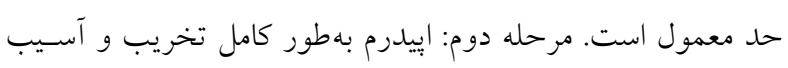

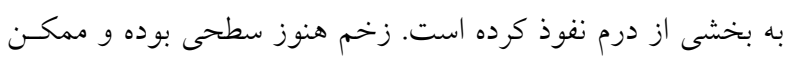

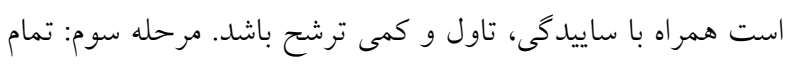

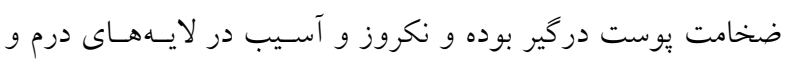

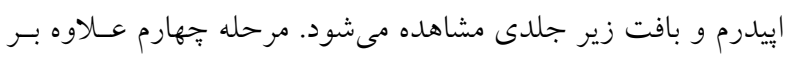

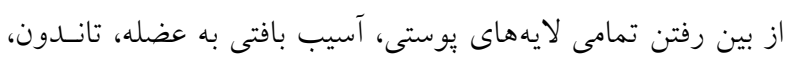

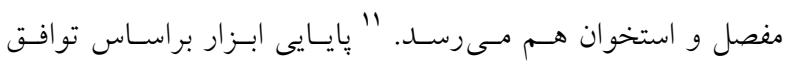

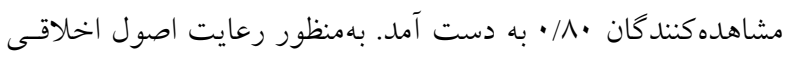

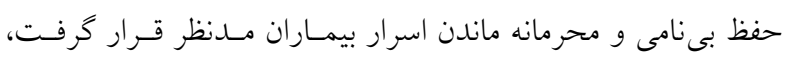




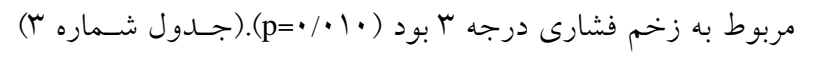

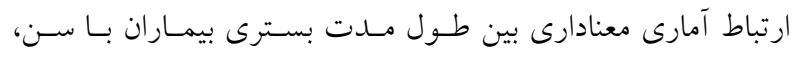

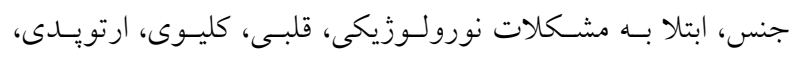
خونى، سرطان و محل زخم مشاهده نشد(ه) (p)
بخش محل بسترى به دست آمد، بطورى كه بيشترين ميانكين طسول

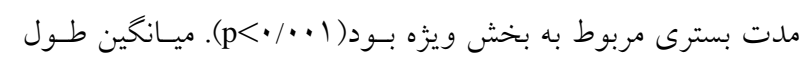

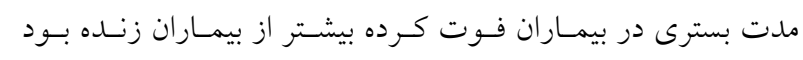
فئاري

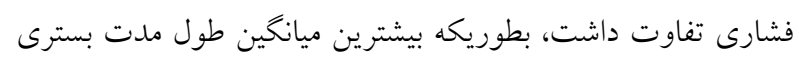

جدول ا: توزيع فراوانى زخم فشارى كسبشده از بيمارستان در سالمندان در سال اجس|

\begin{tabular}{|c|c|c|c|}
\hline فراوانى & درصد & طبقات & متغير \\
\hline 11 & $1 \pi / 9$ & كمتر از • Vم & سن(سال) \\
\hline$\Delta \Delta$ & 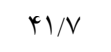 & $\vee \cdot-\lambda \cdot$ & \\
\hline$\Delta 9$ & $\mu \kappa / V$ & بيشتر از •^ & \\
\hline VY & $\Delta \psi / \Delta$ & مرد & 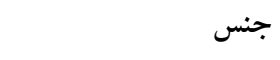 \\
\hline 4. & $r \Delta / \Delta$ & 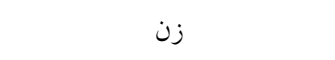 & \\
\hline$\Delta r$ & $4 \cdot / 9$ & داخلى ل & 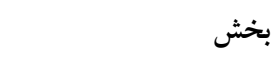 \\
\hline iv & $1 r / 9$ & ويزه(سىسىيو -آى سى يو) & \\
\hline ry & $r Q / \Lambda$ & ارتويدى & \\
\hline 4 & $r / 0$ & اورزانس & \\
\hline r) & $10 / 9$ & وى آى بى & \\
\hline 91 & $9 N / 9$ & ساكروم س & محل زخم \\
\hline rq & $r q / 0$ & اينتر كلوتئال & \\
\hline$r$ & r & ايلياك اي & \\
\hline 9 & $r / 0$ & 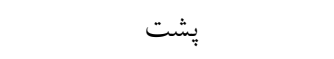 & \\
\hline 1 & $\cdot / 1$ & شانه & \\
\hline r & 1/0 & 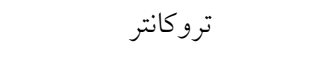 & \\
\hline 1 & $\cdot / \Lambda$ & ل ياشنه يا & \\
\hline 1 & $\cdot / \wedge$ & قوزك خارجى ؛ي & \\
\hline 1 & $\cdot / \wedge$ & ساير ساير & \\
\hline er & 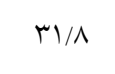 & I & مرحله زخم \\
\hline$\wedge \varphi$ & $90 / T$ & II & \\
\hline$r$ & r & III & \\
\hline . & . & IV & \\
\hline r. & $10 / r$ & بلى بلى & فوت در بيمارستان \\
\hline $11 r$ & $\wedge \kappa / \Lambda$ & 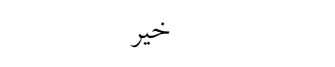 & \\
\hline 1.1 & $v 9 / 0$ & كمتر از ^روز & طول مدت بسترى(روز) \\
\hline rl & $r r / Q$ & بيشتر از ^ روز & \\
\hline
\end{tabular}




\begin{tabular}{|c|c|c|c|c|c|c|}
\hline \multicolumn{2}{|c|}{ نتيجه آزمون } & \multirow{2}{*}{$\frac{\text { كل }}{\ln (\% / 1 \% / 9)}$} & \multirow{2}{*}{ فوتشده } & \multirow{2}{*}{$\begin{array}{c}\text { زنده } \\
\mid r(/ 9 / \Lambda)\end{array}$} & \multirow{2}{*}{ كمتر از · طبقات } & \multirow{2}{*}{ سن(سال) متغير } \\
\hline$X^{2}=r / \cdots r$ & $\mathrm{P}=\cdot / r \mu r$ & & & & & \\
\hline & & $\Delta \Delta(\% / Y \backslash / V)$ & $9(\% / \% / 0)$ & $r q(\% / r V / l)$ & $\vee \cdot-\Lambda \cdot$ & \\
\hline & & $\Delta Q(\% \& Y / V)$ & $9(\% / .9 / 1)$ & $0 \cdot(\% / r V / q)$ & بيشتر از • & \\
\hline \multirow[t]{2}{*}{$X^{2}=\cdot / 990$} & $\mathrm{P}=\cdot / \Delta \wedge \mid$ & $V Y(\% / \Delta Y / \Delta)$ & $11(\% / \Lambda / \Gamma)$ & $41(\% / 4, T)$ & 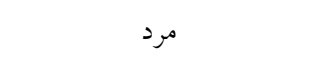 & 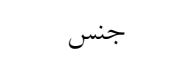 \\
\hline & & $q \cdot(\% / \varphi / \Delta)$ & $9(\% / 9 / 1)$ & $\Delta 1(\% / \Gamma / 9)$ & زن & \\
\hline \multirow{5}{*}{$X^{2}=r \mu / I r \mu$} & $\mathrm{P}<\bullet / \cdots 1$ & $\operatorname{Qr}(\% / \mu \cdot / 9)$ & $q(\% / \% / 0)$ & $\mu \wedge(\% / r G / 4)$ & داخلى & بخش \\
\hline & & $\operatorname{IV}(\% / Y / 9)$ & $\wedge(\% .9 / 1)$ & $9(\% / 9 / 1)$ & ويزه(سىسىيو -آى سى يو) & \\
\hline & & $\mu Y(\%, r \Delta / \Lambda)$ & $\cdot(\cdot)$ & $\mu y(\% / T \Delta / \Lambda)$ & ارتويدى - اري & \\
\hline & & $9(\% / 4 / 0)$ & $y(\%)$ & $r(\% / / \Delta)$ & 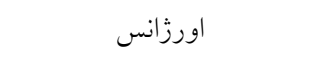 & \\
\hline & & $Y I(\% 10 / 9)$ & $r(\% / / Q)$ & $19(\% / 1 \% / 4)$ & وى آى يى & \\
\hline \multirow[t]{3}{*}{$X^{2}=r Y / 49 Q$} & $\mathrm{P}<\bullet / \cdots 1$ & $\operatorname{Rr}(\% / \mu \mathrm{M} / \Lambda)$ & $r(\% / r / \Gamma)$ & $r q(\% / r q / \Delta)$ & I & مرحله زخم \\
\hline & & $\wedge \varphi(\% / 9 \Delta / r)$ & $1 \Gamma(/ / 9 / \Lambda)$ & $V \Gamma(/ . \Delta \Delta / \Gamma)$ & II & \\
\hline & & $\varphi(r)$ & $\varphi(r)$ & $\cdot(\cdot)$ & III & \\
\hline \multirow[t]{2}{*}{$X^{2}=\cdot / \cdot V{ }^{k}$} & $\mathrm{P}=\cdot / \cdot \varphi \Delta$ & $p V(/ / \mu \Delta / \varphi)$ & $11(\% / \Lambda / \Gamma)$ & $r \varphi(\% / r V / \Gamma)$ & 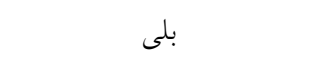 & ابتلا به مشكلات \\
\hline & & $\Lambda \Delta(/ . \xi \psi / \varphi)$ & $9(\% .9 / 1)$ & $V q(/ / .0 V / 9)$ & خير & نورولوزيكى \\
\hline
\end{tabular}

جدول ب: مقايسه ميانخين طول مدت بسترى سالمندان داراى زخم فشارى كسبشده از بيمارستان برحسب متغيرهاى موردبررسى

\begin{tabular}{|c|c|c|c|c|}
\hline & نتيجه آزمون & ميانخين و انحر اف معيار & طبقات & متغير \\
\hline \multirow[t]{3}{*}{$\mathrm{F}=\cdot / T q T$} & $\mathrm{p}=\cdot / \mathrm{VV}$ & $9 / N \pm \Delta / \wedge$ & كمتر از • Vم & سن(سال) \\
\hline & & $9 / \pi \pm \Delta / 9$ & $\vee \cdot-\lambda \cdot$ & \\
\hline & & $\vee / \mu \pm \Lambda / 4$ & بيشتر از • بي & \\
\hline \multirow[t]{2}{*}{$\mathrm{T}=\cdot /$ r } & $\mathrm{p}=\cdot / 411$ & $\vee \pm \Lambda / l$ & 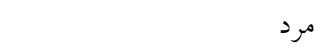 & جنس \\
\hline & & $G / N \pm \Delta / r$ & زن - ت ان & \\
\hline \multirow{5}{*}{$F=\Lambda / v Q r$} & $\mathrm{p}<\bullet / \cdots)$ & $\Delta / \Lambda \pm Y / r$ & 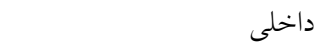 & بخش \\
\hline & & $10 / r \pm 1 \% / 9$ & ويزه(سىسىيو -آى سى يو) & \\
\hline & & $\Delta / \uparrow \pm Y / q$ & 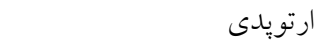 & \\
\hline & & $Y / \Delta \pm Y / 9$ & 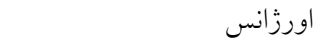 & \\
\hline & & $\Delta / 9 \pm r / \mu$ & وى آى بى & \\
\hline \multirow[t]{3}{*}{$F=r / V \Delta Q$} & $\mathrm{p}=\cdot / \cdot 1$ & $Y / \wedge \pm Y / V$ & I & مرحله زخم \\
\hline & & $\vee / \uparrow \pm \Lambda / 1$ & II & \\
\hline & & $\mid \psi / N \pm q / r$ & III & \\
\hline \multirow[t]{2}{*}{$\mathrm{T}=-\psi / \mu V \psi$} & $\mathrm{p}<\bullet / \cdots 1$ & $\Delta / \wedge \pm \psi+$ & خير & فوت در بيمارستان \\
\hline & & $|Y / \Lambda \pm| Y / 1$ & 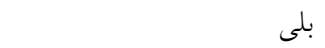 & \\
\hline
\end{tabular}


بيشتر بيماران فوتشده زخم فشـارى درجسهدو داشستند. نتسايج مطالعه ليدر در سال r | • ب نشان داد ابـتلا بـه زخــم بسـتر در طـول مدت بسترى در بيمارستان شانس مرگومير بيمارستانى را I/ T برابر

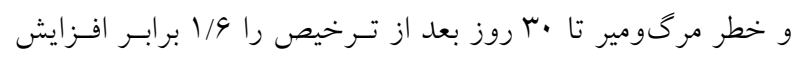
مى 19 در مطالعه حاضر ميانخين طول مـــت بسـترى سـالمندان داراى

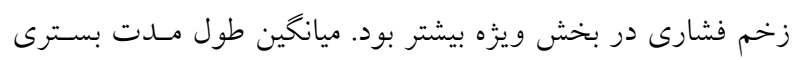

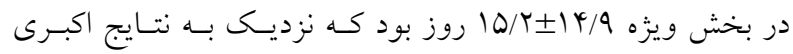

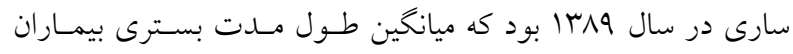

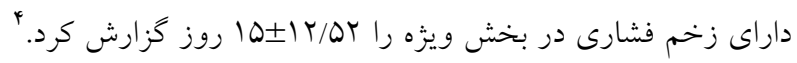
احمدى نزاد مى نويسد بيماران بسترى در بخش هاى مراقبت ويزه بــهـ

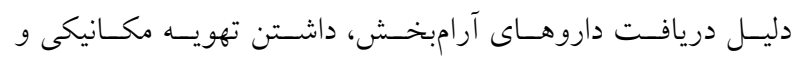
بى تحركى شديد در معرض خطر بيشترى براى بروز زخــم فشـارى قرار دارند. در مطالعه حاضر سالمندانى كه با افزايش طـول مـــت بسـترى شدت زخم فشارى بيشتر مى گردد. در مطالعه كوكس در سال

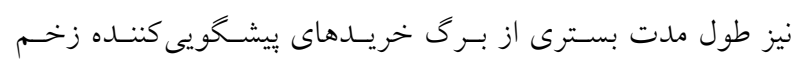

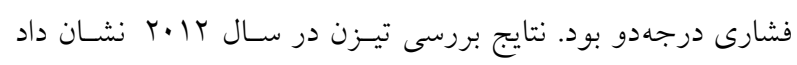

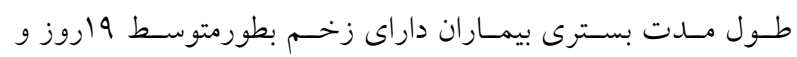

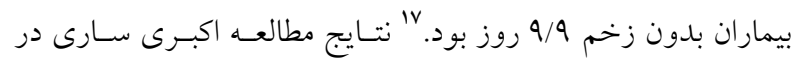
سال 9/1| نشان داد شانس ابتلا به زخم فشارى در بيمارانى كه بين

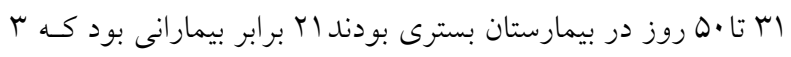

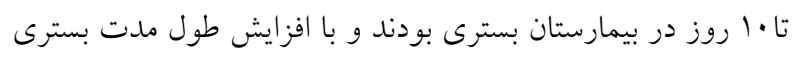

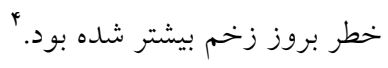

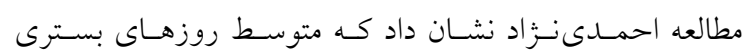

بيمارانى كه دجار زخم فشارى بودند در مقايسـه بـا ديخـــ بيمـاران

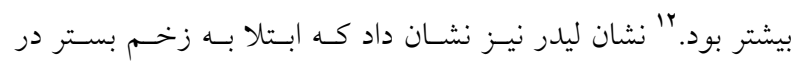
بيمارستان زمان اقامت در بيمارستان و احتمال بسترى مجدد بيمار را

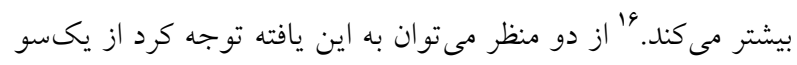

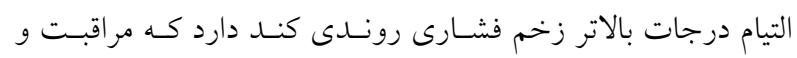

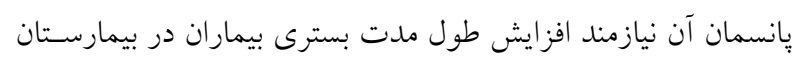

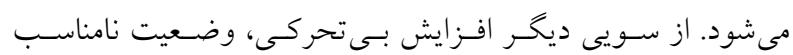

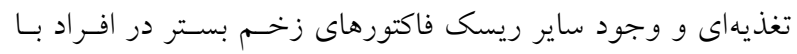

\section{بحث و نتيجه كيرى}

در مطالعه حاضر / / /\% سالمندان دجّار زخم فشــارى در طـول اقامت در بيمارستان فوت كرده بودند. سالانه •9 هزار مـرى در اثـر

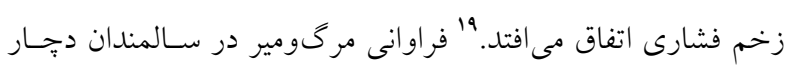
زخم فشارى كسبشده از بيمارستان در مطالعه الـدردن و همكـاران

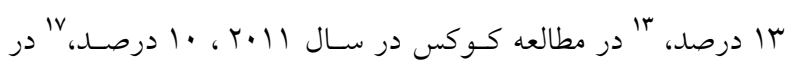

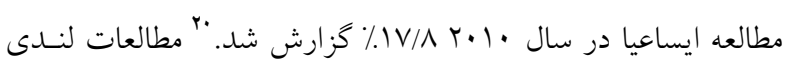

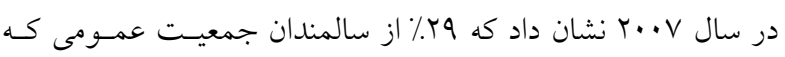
دجّار زخم فشارى بودند، فوت كـرده بودنـد. "r ردليـنَس در سـال

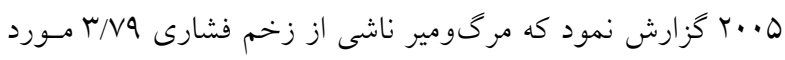

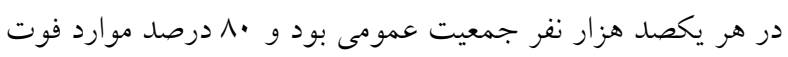
ناشى از زخم فشارى در سـالمندان در سـن بـالاى VD سـال اتفـاق

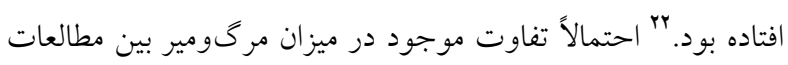

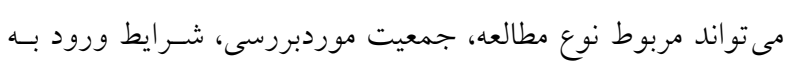

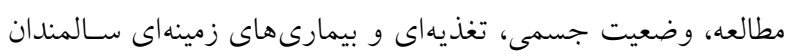
بسترى باشد. در مطالعه حاضر ميانخين طول مــدت بسـترى سـالمندان دجهـار

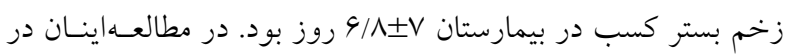

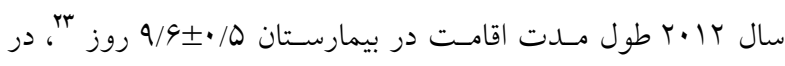

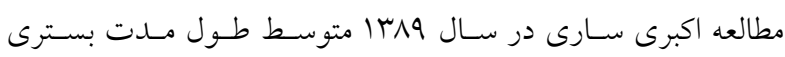

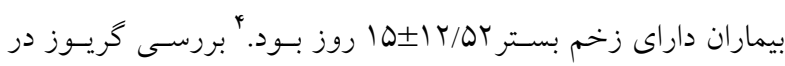

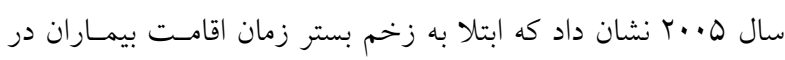

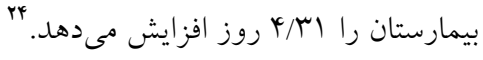

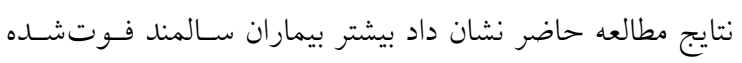

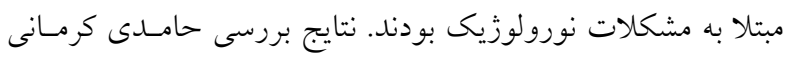

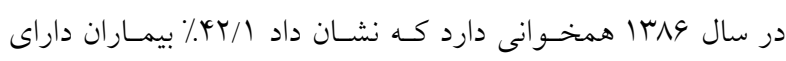

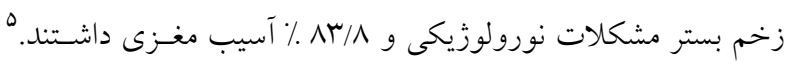
در مطالعه كوكس نيز بيشترين فراوانى زخم بستر در بيمـاران دجهـار

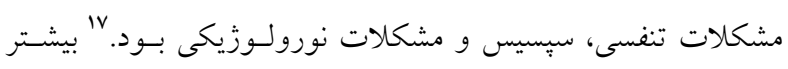
بيماران نورولوزيكى در بخشهاى آى سـى يسو بسـترى مسى شـوند.

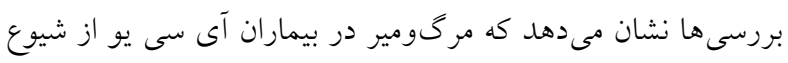

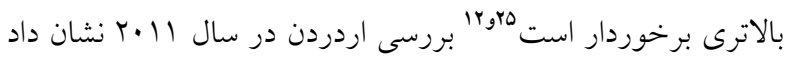

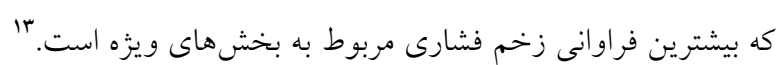




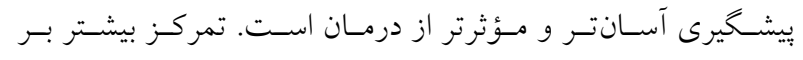

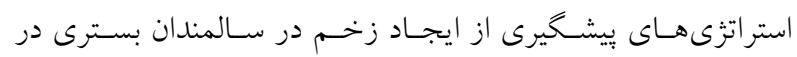

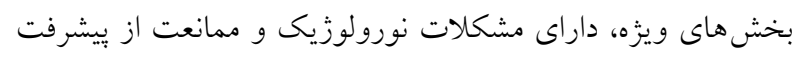

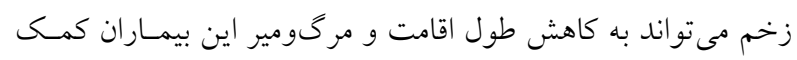

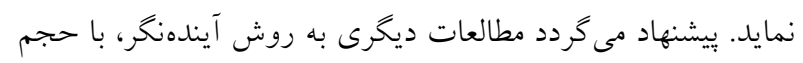

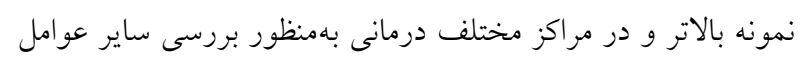

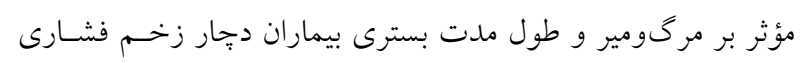

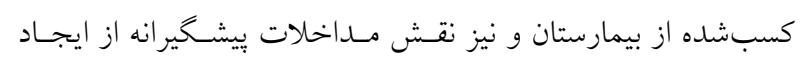
زخم فشارى بر كاهش مرگومير و طـول مــت بسترى سـالمندان بسترى در بخشهـاى ويسرّه و داراى مشـكلات نورولوزيـك انجـام كيرد.

\section{تشكر و قدردانى}

بدين وسيله از همكارى رياسـت محتـرم بيمارسـتان، همكـاران

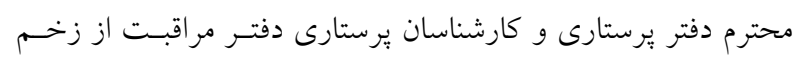
بيمارستان تأمين اجتماعى البرز كرج تشكر و قدردانى مى گرددد.

\section{References}

1. Jamand T, Akaberian S, Khoramroodi R, Pooladi S, Hajivandi A, Bagherzadeh R, Gharibi T, Yazdankhah MR , Zahmatkeshan N , Kamali F. Assessment of risk factors associated with bedsores in patients admitted to Fatemeh Zahra \& Salman Farsi Hospitals in Boushehr by using the braden indices (2007-2008). ISMJ. 2012; 15 (3) :233-40 [In Persian].

2. Meesterberends E, Halfens RJ, Heinze C, Lohrmann C, Schols JM. Pressure ulcer incidence in Dutch and German nursing homes: design of a prospective multicenter cohort study. BMC Nurs. 2011; 28(10):8

3. Dealey C, Brindle CT, Black J, Alves P, Santamaria N, Call E, Clark M. Challenges in pressure ulcer prevention. Int Wound J. 2013 ; 20.12(3):309-12.

4. Akbari Sari A, Beheshti Zavare Z, Arab M, Rashidian A, Golestan B. Factors affecting pressure ulcer in the ICU units of Tehran University of Medical Sciences teaching hospitals. Journal of School of Public Health and Institute of Public Health Research. 2010; 8(3): 81-92 [In Persian].

5. Reihani H, Haghiri A. Determination of bed sore risk factors in craniospinal trauma patients in intensive care

$$
\begin{aligned}
& \text { وخامت بيمارى بيشتر و طول مدت بسترى بـالاتر موجـب تشـديد } \\
& \text { درجه زخم فشارى مى گردد. } \\
& \text { مطالعه حاضر نشان داد طول مدت بسترى درى در بيماران فوتشـــه }
\end{aligned}
$$

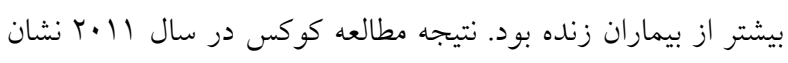

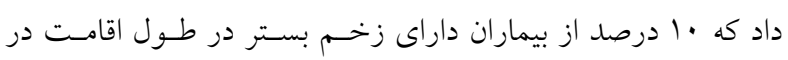

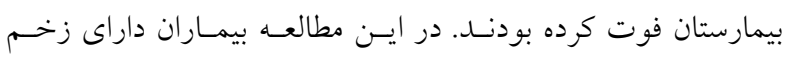

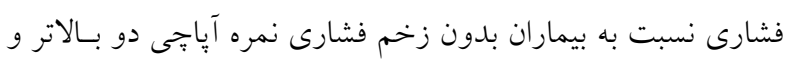

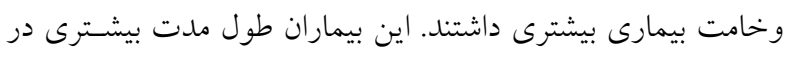

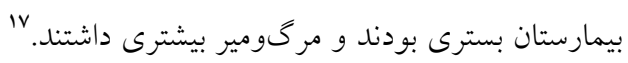

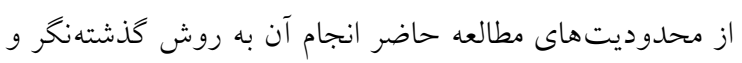

$$
\begin{aligned}
& \text { جمع آورى داده از يك مركز درمانى بود. }
\end{aligned}
$$

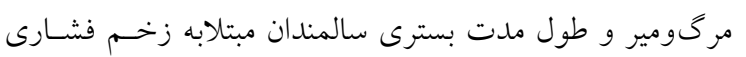

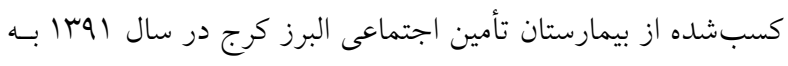

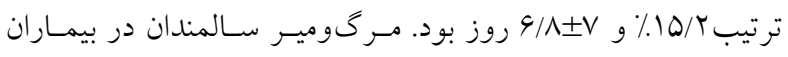

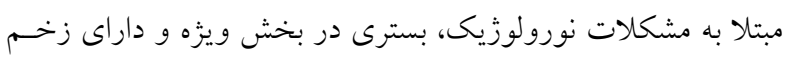

$$
\begin{aligned}
& \text { بستر درجهدو بيشتر بود. همجنين طول مدت بسترى در سـالمندان } \\
& \text { بخش هاى ويزه، فوتشده و داراى زخم بستر درجه سه بالاتر بـود. }
\end{aligned}
$$

units. Arak University of Medical Sciences Journal. 2007; 10 (2):39-46 [In Persian].

6. Esmaili R, Ebrahim zadeh M, Khalilian A, Nasiri E, Jafari H, Dehghani O et al . Study regarding the effect of calendula officinalis cream in healing of pressure sores. $\mathrm{J}$ Mazandaran Univ Med Sci. 2008; 18 (66):19-25 [In Persian].

7. Soozani A, Khosravi A, Pourheydari M, Montazeri A. Using braden and waterlow scales to predict pressure ulcer: a comparative study. Knowledge \& Health. Journal of Shahroud University of Medical Sciences. 2010;5(4):43-7 [In Persian].

8. Moore Z, Cowman S. Pressure ulcer prevalence and prevention practices in care of the older person in the Republic of Ireland. J Clin Nurs. 2012;21(3-4):36271.

9. Theisen S, Drabik A, Stock S. Pressure ulcers in older hospitalised patients and its impact on length of stay: a retrospective observational study. Clin Nurs. 2012; 21(34):380-7.

10. Gist S, Tio-Matos I, Falzgraf S, Cameron S. Wound care in the geriatric client. Clinical Interventions in Aging 2009:4 269-87. 
11. Baumgarten M, Margolis DJ, Localio AR, Kagan SHLowe RA, Kinosian B, Abbuhl SB, Kavesh W, HolmesJH, Ruffin A, Mehari T. Extrinsic risk factors for pressure ulcers early in the hospital stay:a nested casecontrol study. J Gerontol A Biol Sci Med Sci. 2008; 63(4): 408-13.

12. Ahmadi Nejad M, Rafiei H. Pressure ulcer incidence in ICU patients in Bahonar Hospital, Kerman. J Iran Soc Anaesthesiol Intensive Care 2010; 57:10-6 [In Persian]

13. Alderden J, Whitney JD, Taylor SM, Zaratkiewicz S. Risk profile characteristics associated with outcomes of hospital-acquired pressure ulcers: a retrospective review. Crit Care Nurse. 2011;31(4):30-43.

14. Baumgarten M, Margolis DJ, Localio AR, Kagan SH, Lowe RA, Kinosian B, Holmes JH, Abbuhl SB, Kavesh W, Ruffin A. Pressure ulcers among elderly patients early in the hospital stay. J Gerontol A Biol Sci Med Sci. 2006; 61(7):749-54.

15. Baumgarten M, Margolis DJ, Orwig DL, Shardell MD, Hawkes WG, Langenberg P, Palmer PH, Jones PS, McArdle PF, Sterling R, Kinosian BP, Rich SE, Sowinski J, Magaziner J. Pressure ulcers in elderly hip fracture patients across the continuum of care. J Am Geriatr Soc. 2009; 57(5): 863-70.

16. Lyder CH, Wang Y, Metersky M, Curry M, Kliman R, Verzier NR, Hunt DR. Hospital-acquired pressure ulcers: results from the national Medicare Patient Safety Monitoring System study. J Am Geriatr Soc. 2012; 60(9):1603-8

17. Cox J. Predictors of pressure ulcers in adult critical care patients. Am J Crit Care. 2011; 20(5):364-75.

18. Dealey C, Posnett J, Walker A. The cost of pressure ulcers in the United Kingdom. J Wound Care. 2012; 21(6):261-6.

19. Aizpitarte Pegenaute E, Garcia de Galdiano Fernandez A , Zugazagoitia Ciarrusta N.Pressure ulcers in intensive care: assessment of risk and prevention measures. Enferm Intensiva 2005; 16: 153-63.

20. Isaia G, Scarafiotti C, Michelis G. The experience of a geriatric hospital at home service for acutely ill elderly patients with pressure ulcers: an observational study. Wounds. 2010; 22(5):121-6.

21. Landi F, Onder G, Russo A, Bernabei R. Pressure ulcer and mortality in frail elderly people living in community. Archives of Gerontology and Geriatrics.2007;44: 217-23.

22. Redelings MD, Lee NE, Sorvillo F. Pressure ulcers: more lethal than we thought? Adv Skin Wound Care. 2005; 18(7):367-72.

23. Inan DG, Oztunç G. Pressure ulcer prevalence in Turkey: a sample from a university hospital. J Wound Ostomy Continence Nurs. 2012; 39(4):409-13.

24. Graves N, Birrell F, Whitby M.Infection Control and Hospital Epidemiology.2005; 26(3): 293-7.

25. VanGilder C, Amlung S, Harrison P, Meyer S. Results of the 2008-2009 International Pressure Ulcer Prevalence Survey and a 3-year acute care, unit-specific analysis. Ostomy Wound Manage. 2009; 55(11):39-45. 